\title{
Beyond the Tarmac Road: a Guide for Rural Poverty Watchers
}

\author{
Mick Moore
}

In the conferences on Rapid Rural Appraisal the tarmac or main road bias' has frequently been listed among the biases affecting the outsiders observations and perceptions of rural poverty. The wheel-bound outsider tends to see and meet only those rural people whose front doors can be approached by car or jeep. Such households may not be typical of rural areas. In particular, it has been suggested that they tend to be less poor than those in less accessible areas. In this article this latter point is illustrated by the following piece of evidence.

In 1976-78 the author and Ceylonese colleagues were involved in field research in three rural localities in the southwestern coastal zone of Sri Lanka. The area is, at least by Asian standards, relatively well provided with roads, public transport, electricity. and a variety of public infrastructure. Each of the three localities is fairly riddled with motor roads, some of them tarred bus routes. Few houses are located more than half a mile from a motor road.

There is a wide diversity of house types, ranging from spacious, many-roomed structures with tiled roofs and cemented walls and floors down to fragile one-roomed huts made of cadjans (coconut fronds) on beaten earth floors. As we shall see below, house types are closely related to income levels. The simplest single criterion of house type is the type of flooring: cemented or earth. (In fact cemented floors almost always indicate cemented walls and tiled roofs and earth floors cadjan roofs and cadjan or mud walls.) The proportion of houses with earth floors ranged from 14 per cent in one locality to 41 per cent in another. The remarkable fact is that one could drive along all the roads in these localities and see scarcely a single mud floored house.

Conclusion. The poor are indeed invisible.

To conclude that accurate and representative rural appraisal must involve a little leg work to overcome roadside bias would take one a long way in the right direction. The concept of 'roadside bias' does not, however, fully encapsulate the kinds of processes leading to micro-level differences in the location of rich and poor in rural Sri Lanka. The issue is worth pursuing further, not least because it provides this sociologist with an opportunity to illustrate the indispensibility of the sociological perspective.
The location of rich and poor reflects in part the outcome of social processes rooted in Ceylonese history and culture (Moore and Perera 1978). Unlike in much of South Asia, dispersed settlement is the statistical and evaluative norm among Ceylonese. Each household or group of related households prefers to live in its own homestead surrounded by coconut and fruit trees.

Population growth has led to the expansion of 'villages into previously unsettled areas. The newly-settled

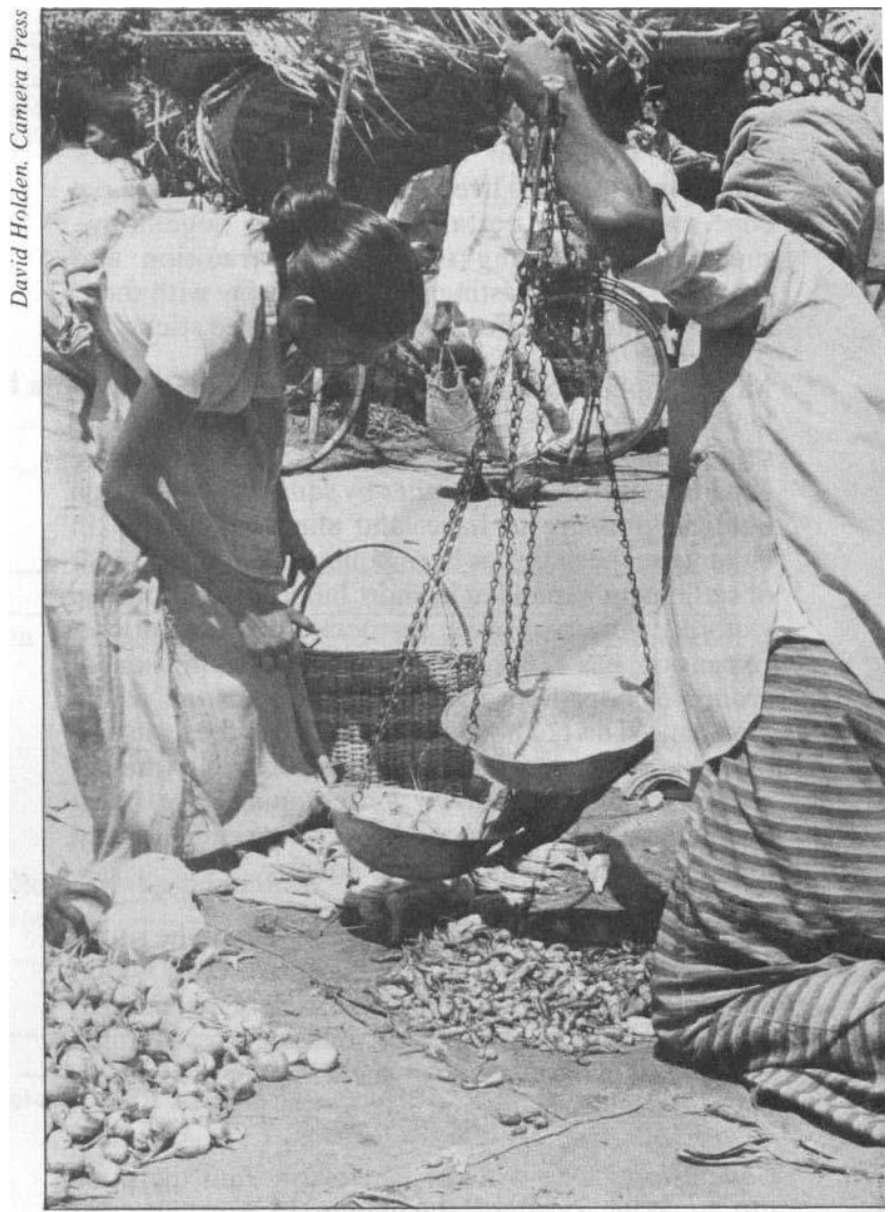


areas are generally less attractive than those already occupied: they are hillier, rockier, have less fertile land and involve greater difficulties in obtaining water. Also, it tends to be the poorer members of society who move onto the fringes of their villages. They have less property to tie them to the village centres and less money with which to purchase land there. The village centres reflect the importance of non-agricultural livelihoods and of the ties to the wider society and economy. It is here that one finds bus services, shops, post offices, schools, rural banks, the homes of people employed in public service and the urban economy. In this respect it should be noted that rural Sri Lanka is relatively more commercialised and dependent on non-agricultural occupations, including public service, than many developing rural areas. Non-agricultural jobs are often more remunerative than agriculture.

There is a clear sense of 'core' and 'periphery' in the relationships between the older village centres and the more recently settled areas. The periphery is both subordinate to and dependent upon the core in several senses: for access to public infrastructure and commercial services; by virtue of the fact that the land and property owners on whom the poor depend for employment tend to live in the core; and because the core exercises a certain 'ideological hegemony', successfully claiming to represent tradition and property, and contrasting itself favourably with those less desirable elements who live 'out in the sticks'.

Most peripheral village expansion has taken place on land owned by the Crown, and in principle closed to settlement. De facto rights to use such land have generally been acquired either by squatting or through political pressure to have land alienated legally. In either case the issue has been political, and the frontier of settlement expanded in short bursts as the political victories were won over restrictive administrations. Expansion has often involved the concentration of groups of poor households in a new area all at the same time. This has not been conducive to the evolution of stable or structured social relationships. Areas of recent expansion, known as 'colonies', are often characterised by loose social control, criminality and immorality, as well as material poverty.

There can be very substantial differences in the social character and composition of localities even within the same village. In a spatial sense society resembles a patchwork quilt. The notion of 'roadside bias' captures a great deal of the diversity on the rich-poor continuum, but not necessarily all.

Conclusions. One will not necessarily find the poor just by taking a path off the main road. Further, even the locals may not be a reliable guide: those from the 'core', in particular, may have very little idea of the location of the peripheries and their personalities and numbers.

Apart from the roadside issue, the core can exercise a great pull on the outsider who decides to do a few days' or a week's fieldwork. Apart from the facilities and the sense of being at the strategic hub of local affairs, it can claim a sense of history and tradition, to which sociologists especially appear vulnerable. ${ }^{1}$

Among the various proxy variables for income or wealth, standards of housing are among the most obvious and popular. This author has followed this practice. Since direct income and wealth data were not collected, there is no absolute way of confirming the validity of this proxy. However, a number of pieces of evidence strongly suggest that housing is indeed a good proxy for income. Tables 1-3 relate to 60 households in one of the localities studied. These were households which the author or his colleagues had been regularly visiting and interviewing about twice a week for a year before data on political preferences were sought.

Table 4 relates to 1,144 persons in the three localities studied: those aged 10-34 years who had completed schooling and not yet married. Married persons were excluded because (a) they sometimes came from a different village and (b) marriage might involve moving out of the parental home, thus disguising the relationship which is of interest here.

The remarkably high degree of social and political polarisation suggested by these figures is of only incidental interest here. It is however helpful in drawing inferences. Housing standards, impressionisticallyderived income levels and paddy land rights are all good predictions of political party support. By inference, they are all strongly related to one another. Ability to pursue formal education is also very closely related to housing standards.

Conclusion. Housing standards are good proxies for income levels. This is least true for younger couples recently married. Those from wealthy backgrounds sometimes live in houses of poor standards for a few years until they are able to build up and improve them.

There is for Sri Lanka, and perhaps many other countries, a Housing Census which provides data on housing materials at the level of relatively small administrative units.

Conclusion. The Housing Census provides a good base against which to measure success in the war against roadside and other kinds of anti-poor observational bias.

${ }^{1}$ Sociologists writing on rural Sri Lanka have mostly focused on 'core' area, and completely ignored the peripheries (see Moore 1979). 


\section{Housing standards and political affiliation (1977 general election $)^{\mathrm{a}}$}

\begin{tabular}{lcccc}
\hline Political Party supported: & Right-wing $^{b}$ & Centre & Left-wing $^{\text {b }}$ & \\
\hline Households with cement floors & 17 & 17 & 8 & 42 \\
Households with earth floors & 3 & 8 & 7 & 18 \\
\hline All households & 20 & 25 & 15 & 60 \\
\hline
\end{tabular}

a Most households appeared unanimous in supporting one party. Others have been excluded from these tabulations.

b $\quad$ Right-wing = United National Party; Centre = Sri Lanka Freedom Party; Left-wing = Lanka Socialist Party (LSSP).

table 2

Impressionistically-derived income categories and political affiliation (1977 general election)

\begin{tabular}{lcccc}
\hline Political Party supported: & Right-wing & Centre & Left-wing & Total \\
\hline Richer households $^{c}$ & 11 & 7 & - & 7 \\
Medium households $c$ & 9 & 6 & 8 & 22 \\
Poorer households $^{c}$ & - & 12 & 15 & 20 \\
\hline All households & 20 & 25 & 60 \\
\hline
\end{tabular}

c This categorisation was achieved by asking two research assistants individually to classify households into three categories of approximately equal size, and then discuss and reconcile discrepancies. This took place after a year's acquaintance with the villagers.

table 3

\section{Rights in paddy land ${ }^{a}$ and political affiliation ( 1977 general election)}

\begin{tabular}{lcccc}
\hline Political Party supported: & Right-wing & Centre & Left-wing & Total \\
\hline Paddy land owners & 14 & 13 & 4 & 31 \\
Paddy land tenants & 5 & 4 & 3 & 12 \\
Landless & 1 & 8 & 8 & 17 \\
\hline All households & 20 & 25 & 15 & 60 \\
\hline
\end{tabular}

a Paddy land is not the sole or even the main item of capital in this region. It does however, have important extra-economic significance and is sought after (Moore 1979).

table 4

\section{Housing standards and educational attainments}

\begin{tabular}{lrrrc}
\hline School grade attained: & $0-5$ & $6-10$ & $11+$ & Total \\
\hline Persons from HHs with cement floors & 45 & 275 & 79 & 399 \\
Persons from HHs with earth floors & 319 & 402 & 24 & 745 \\
\hline All persons & 364 & 677 & 103 & 1144 \\
\hline
\end{tabular}

NB These figures indicate that a person living in a cement-floored house is more than six times as likely to continue in school beyond grade 10 as a child from an earth-floored house.

\section{References}

Moore, M. P. and U. L. J. Perera, 1978, 'Land Policy and Village Expansion in Sri Lanka', Marga (Colombo), 5(1)
Moore, M. P., 1979, 'Ideology and Property in Rural Malagasy and Sri Lanka', mimeo 